\title{
Effect of a Non-polymer Titanium Dioxide Thin Film-Coated Stent with Heparin in a Porcine Coronary Restenosis Model
}

\author{
Kyung Seob Lim, ${ }^{1,2,3}$ Myung Ho Jeong, ${ }^{1,2,3,4}$ In Ho Bae, ${ }_{1}^{1,2}$ Jun-Kyu Park, Dae Sung Park ${ }_{1}^{2,3}$ Jae Won Shim, ${ }_{1}^{2,3}$ Han Byual Kim, ${ }_{1}^{2,3}$ Mi Rim Jin, ${ }^{2,3}$ Hyun Kuk Kim, ${ }^{6}$ \\ Sung Soo Kim, ${ }^{6}$ Min Chul Kim, ${ }^{2,3}$ Doo Sun Sim, ${ }^{2,3}$ Young Joon Hong, ${ }^{2,3}$ Ju Han Kim, ${ }^{2,3}$ Youngkeun Ahn ${ }^{2,3}$ \\ 'Korea Cardiovascular Stent Institute, Jangsung, Korea \\ ${ }^{2}$ Cardiovascular Convergence Research Center, Nominated by the Korea Ministry of Health and Welfare, Gwangju, Korea \\ ${ }^{3}$ Cardiovascular Research Center, Chonnam National University Hospital, Gwangju, Korea \\ ${ }^{4}$ Regeneromics Research Center, Chonnam National University, Gwangju, Korea \\ ${ }^{5}$ CGBio. Co. Ltd, Jangseong-gun, Korea \\ ${ }^{6}$ Division of Cardiology, Chosun University Hospital, Gwangju, Korea
}

Received: 1 September 2017

Accepted: 13 November 2017

${ }^{*}$ Corresponding author:

Myung Ho Jeong, MD, PhD, FACC, FAHA, FESC, FSCAI

Director of Korea Cardiovascular Stent Research Institute, Director of

Cardiovascular Convergence Research

Center Nominated by Korea Ministry of Health and Welfare, 671 Jaebong-ro,

Dong-gu, Gwangju 61469, Korea

Tel: +82-62-220-6243

Fax: +82 62-228-7174

E-mail: myungho@chollian.net,

mhjeong@chonnam.ac.k
Copyright (C) Korean Society on Thrombosis and Hemostasis. All rights reserved.

\begin{abstract}
Purpose: The aim of this study was to examine the effect of non-polymer titanium dioxide $\left(\mathrm{TiO}_{2}\right)$ thin filmcoated stents modified with heparin in a porcine coronary overstretch restenosis model.

Methods: Pigs were randomized into three groups in which either $\mathrm{TiO}_{2}$ film-heparin coated stent (THS, $n=12)$, zotarolimus-eluting stent with polymer (ZES, $n=12)$, or bare metal stent (BMS, $n=12$ ) was placed in a coronary artery (18 pigs, 12 coronaries in each group). Histopathologic analysis was performed at 28 days after stenting.

Results: There was no significant difference in injury score among the three groups. There were significant differences in neointima area $\left(2.9 \pm 0.85 \mathrm{~mm}^{2}\right.$ in the THS group vs. $2.8 \pm 0.10 \mathrm{~mm}^{2}$ in the ZES group vs. $3.3 \pm 0.58 \mathrm{~mm}^{2}$ in the BMS group, $P<0.05$ ), fibrin score ( 0.0 [range 0.0 to 1.0 ] in the THS group vs. 2.0 [range 2.0 to 2.0 ] in the ZES group vs. 0.5 [range 0.0 to 2.0 ] in the BMS group, $P<0.0001$ ), and inflammation score (1.0 [range $0.0-1.0$ ] in the THS group vs. 1.0 [range 1.0 to 2.0 ] in the ZES group vs. 1.0 [range 0.75 to 1.0 ] in the BMS group, $P<0.0001$ ) among the three groups. In-stent restenosis rate, as measured by micro computed tomography, demonstrated similar percent area values upon histology analysis $(57.7 \pm 13.14 \%$ in the THS group vs. $58.7 \pm 16.44 \%$ in the ZES group $64.8 \pm 8.56 \%$ in the BMS group, $P<0.05$ ).

Conclusion: THS is more effective in reducing neointima formation compared to BMS. Moreover, the neointima suppressive effect of THS exceeds that of commercial ZES, with lower fibrin and inflammation scores in a porcine coronary restenosis model.
\end{abstract}

Keywords: Stents, Percutaneous coronary intervention, Restenosis, Inflammation

\section{Introduction}

First-generation drug-eluting stents (DES) have successfully solved the problems related to the high restenosis rate of bare metal stents (BMS). However, those improvements were accompanied by an increased risk of delayed re-endothelialization and stent thrombosis (ST) ${ }^{1,2}$ The shortcomings of ST and poor re-endothelialization might be related to the polymers used for drug coating on BMS. ${ }^{3-5}$ To address this problem, a more biocompatible polymer and thin stent strut of cobalt-chromium alloy were applied in next-generation DES. ${ }^{6}$ Therefore, the ST of second-generation DES was significantly lower than that of first-generation DES. ${ }^{7}$ However, the remaining polymer after drug release might still have potential risk for occurrences such as polymer-induced inflammation.

So, we developed a polymer-free drug-combining technology to reduce the side effects of polymer-based DES. Titanium has been used for improving the blood compatibility of medical devices, such as coronary stents, artificial valves, and ventricular assist devices (VAD).

Heparin offers an anticoagulation effect and inhibits vascular smooth muscle cell (VSMS) proliferation. ${ }^{8-12}$
The aim of the present study was to evaluate the effect of the nonpolymer titanium dioxide $\left(\mathrm{TiO}_{2}\right)$ thin film-coated stent with heparin in a porcine coronary overstretch restenosis model.

\section{Methods}

\section{Materials}

Porcine intestinal-mucosal sodium salt heparin (grade 1-A; 181 usp units/mg) was used in this study. Heparin sodium salt was purchased from Sigma-Aldrich Co. (USA). All other reagents were of analytical grade.

Preparation of $\mathrm{TiO}_{2}$ film-heparin coated stent $\mathrm{A} \mathrm{TiO}_{2}$ thin film was deposited onto a bare metal stent $(3.0 \mathrm{~mm} \times 16$ $\mathrm{mm}$, cobalt-chromium alloy) by a plasma-enhanced chemical vapor deposition (PECVD) process, and its potential as a drug-combining matrix was investigated. When deposited at a discharge power of 5 $\mathrm{W}$, the film showed a highly smooth surface with a roughness of 9.4 $\mathrm{nm}$, adequate mechanical stability with good adhesion, and good blood compatibility. The film was surface-modified with water plasma to introduce hydroxyl groups on the $\mathrm{TiO}_{2}$ surface. Then, drugs 
could be chemically grafted onto the modified surface through the formation of ester bonds between hydroxyl groups on the modified $\mathrm{TiO}_{2}$ film and carboxyl groups in the heparin. When heparin was grafted onto the $\mathrm{TiO}_{2}$-deposited and surface-modified stents, the grafted amount was measured to be $53.9 \mu \mathrm{g}$ on average. In the in vitro drug-release test, heparin was released continuously for four weeks. $^{13}$

\section{Animal preparation and stent implantation}

The animal study was approved by the Ethics Committee of Chonnam National University Medical School and Chonnam National University Hospital (CNU IACUC-H-2012-24) and conformed to the Guide for the Care and Use of Laboratory Animals published by the US National Institutes of Health (NIH Publication No. 85-23, revised 1996). Study animals were castrated male pigs weighing 20$25 \mathrm{~kg}$. To prevent acute thrombosis after stenting, daily pre-medication with aspirin $(100 \mathrm{mg})$ and clopidogrel $(75 \mathrm{mg})$ was administered for five days before the procedure. On the procedure day, pigs were anesthetized with zolazepam and tiletamine $(2.5 \mathrm{mg} / \mathrm{kg}$, Zoletil $50^{\circledR}$, Virbac, Caros, France), xylazine ( $3 \mathrm{mg} / \mathrm{kg}$, Rompun ${ }^{\circledR}$, Bayer AG, Leverkusen, Germany), and azaperone $\left(6 \mathrm{mg} / \mathrm{kg}\right.$, Stresnil ${ }^{\circledR}$, Janssen-Cilag, Neuss, Germany). The pigs received continuous supplemental oxygen through an oxygen mask. Subcutaneous 2\% lido- caine at the cut-down site was administered, the left carotid artery was surgically exposed, and a 7-French sheath was inserted.

Continuous hemodynamic and surface electrocardiographic monitoring was maintained throughout the procedure. Then, 5,000 units of heparin were administered intravenously as a bolus prior to the procedure, the target coronary artery was engaged using standard 7-F guide catheters, and control angiograms of both coronary arteries were performed using a non-ionic contrast agent in two orthogonal views.

The stent was deployed by inflating the balloon to a stent-to-artery ratio of 1.3:1. Coronary angiograms were obtained immediately after stent implantation. Then, all equipment was removed, and the carotid artery was ligated.

Four weeks after stenting, the animals underwent follow-up angiography using the same orthogonal views before death via $20 \mathrm{~mL}$ of potassium chloride intracoronary injection.

The hearts were removed, and the coronary arteries were pressure-perfusion fixed at $110 \mathrm{mmHg}$ in $10 \%$ neutral buffered formalin overnight. Each of 10 stented arteries was step-sectioned, processed routinely for light microscopy, and stained for histological analysis. All specimens were evaluated by micro-computerized tomography (M-CT). Two specimens each from the three groups was analyzed by scanning electron microscopy (SEM).
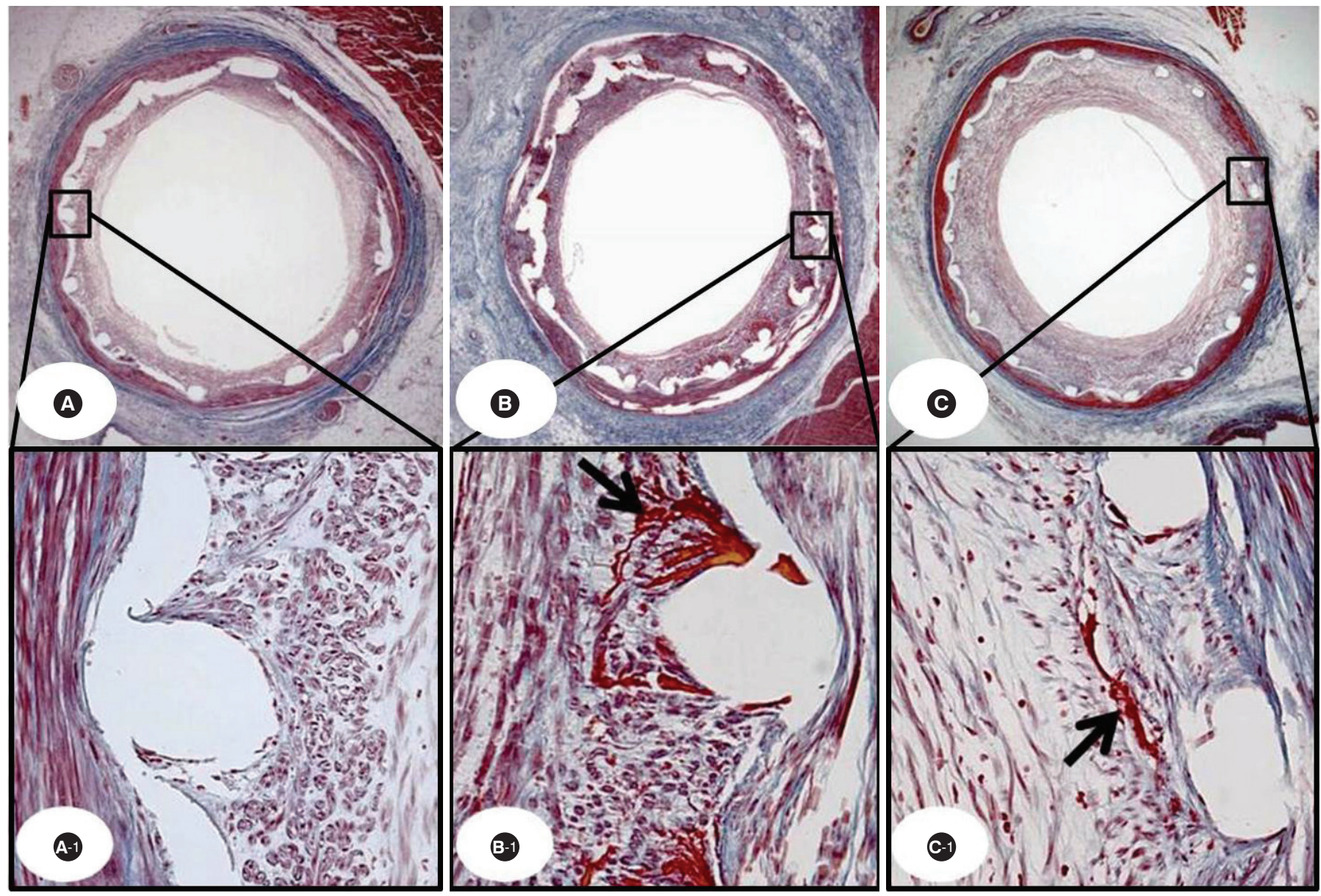

Fig. 1. The Carstair fibrin stain of the low- and high-power fields (magnitude, 20x, 200x) showing fibrin infiltration in THS implant (A, A-1), ZES implant (B, B-1), and BMS implant (C, C-1) cases. Black arrow indicates fibrin deposition.

$\mathrm{THS}, \mathrm{TiO}_{2}$ film-heparin coated stent; ZES, zotarolimus-eluting stent with biocompatible polymer; BMS, bare metal stent. 
Study groups

The pigs were randomly divided into three groups: group $1\left(\mathrm{TiO}_{2}\right.$ film-heparin coated stent, THS, $3.0 \mathrm{~mm} \times 16 \mathrm{~mm}, \mathrm{n}=12$ ), group 2 (zotarolimus-eluting stent with biocompatible polymer, ZES, Endeavor Resolute ${ }^{\circledR}$, Medtronic CardioVascular, Minneapolis, MN, USA, $3.0 \mathrm{~mm} \times 16 \mathrm{~mm}, \mathrm{n}=12)$, and group $3(\mathrm{BMS}, 3.0 \mathrm{~mm} \times 16 \mathrm{~mm}$, $\mathrm{n}=12)$.

A total of 18 pigs were used in this study (18 pigs, 36 coronary arteries, 12 coronary arteries in each group). A THS, a ZES, and a BMS were implanted in the left anterior descending artery and left circumflex artery in a randomized manner.

Histopathologic, scanning electron microscopy, and microcomputed tomography analysis

Histopathologic evaluation of each artery was performed by an experienced cardiovascular pathologist. The specimens were embedded, and sections of 3-4 $\mu \mathrm{m}$ thickness were obtained at approximately $1 \mathrm{~mm}$ intervals. Sections were then stained with hematoxylin-eosin and Carstairs' for histological analysis. Measurements of the histopathologic sections were performed using a calibrated microscope, digital video imaging system, and microcomputer program (Visus 2000 Visual Image Analysis System, IMT Tech, CA, USA). Borders were manually traced for lumen area, area circumscribed by the internal elastic lamina, and the innermost border of the external elastic lamina (external elastic lamina area). Morphometric analysis of the neointimal area for a given vessel was calculated as the measured internal elastic lamina area minus the lumen area. The measurements were performed on five cross-sections from the proximal and distal ends and three midpoints of each stented segment. Histopathologic stenosis was calculated as $100 \times(1-$ [lesion lumen area/lesion internal elastic lamina area]). ${ }^{14}$ The harvested stent specimen was stored in formaldehyde solution. A 1.5-mL Eppendorf tube was filled with clay to form it into a V shape to hold the stent during contrast agent staining. The stents were removed from the solution and placed vertically in the V-shaped opening in the clay. Each stent had to be fixed with clay such that there was no movement of the stent inside the Eppendorf tube. The contrast agent used was omnihexol. One milliliter of contrast agent was placed in a 5-mL syringe and injected through the opening at the center of the stent. The stent was incubated with contrast agent overnight and subjected to M-CT imaging. ${ }^{15}$ After performing M-CT analysis, the longitudinally cut sections were rinsed three times using sodium phosphate, fixed in $1 \%$ osmium tetroxide, and then rinsed in distilled water. The specimens were dehydrated in a graded series of alcohols, critically point dried, placed in a vacuum coater, and coated with $30-40$ $\mathrm{nm}$ gold. Luminal surfaces were SEM photographed at $100 \times$. Pho-
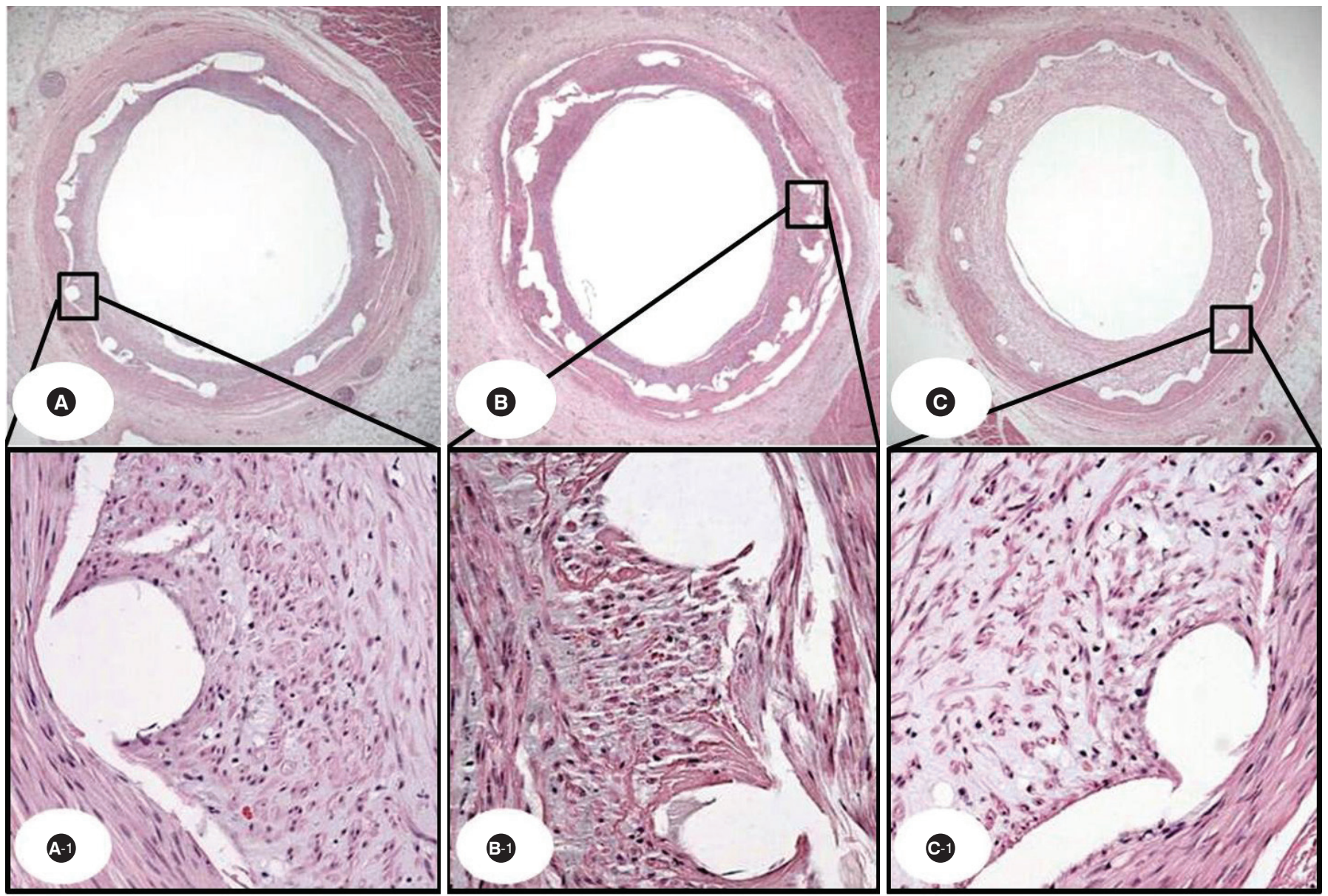

Fig. 2. Representative images of hematoxylin and eosin staining at four weeks after stenting. Specimen THS implanted (A: 20x, A-1: 200x), ZES implanted (B: 20x, B-1: $200 \times$ ), and BMS implanted (C: 20x, C-1: 200x).

$\mathrm{THS}, \mathrm{TiO}_{2}$ film-heparin coated stent; ZES, zotarolimus-eluting stent with biocompatible polymer; BMS, bare metal stent. 
tographs were digitized, and the strut coverage was observed. ${ }^{16}$ All results were interpreted by two independent pathologists in a blinded fashion.

Evaluation of arterial injury

Arterial injury at each strut site was determined by the anatomic structures penetrated by each strut. A numeric value was assigned as previously described by Schwartz et al. ${ }^{14}$ : $0=$ no injury, $1=$ break in the internal elastic membrane, $2=$ perforation of the media, and 3 =perforation of the external elastic membrane to the adventitia. The average injury score for each segment was calculated by dividing the sum of injury scores by the total number of struts at the examined section.

Evaluation of inflammation scores, neointimal reaction, and fibrin score

With regard to the inflammation score for each individual strut, the following grading system was used: $0=$ no inflammatory cells surrounding the strut, $1=$ light, non-circumferential lymphohistiocytic infiltrate surrounding strut, $2=$ localized, moderate to dense cellular aggregate surrounding the strut non-circumferentially, and $3=$ circumferential dense lymphohistiocytic cell infiltration of the strut. The inflammation score for each cross section was calculated by dividing the sum of the individual inflammation scores by the total number of struts at the examined section. ${ }^{17}$ Ordinal data for fibrin were collected on each stent section using a scale of 0 to 3 , as previously reported. ${ }^{18}$
Statistical analysis

Statistical analysis was performed with the aid of the commercially available software (SPSS Version 15, Chicago, IL, USA). The data were presented as mean value \pm SD. Unpaired Student's $t$ test was used for the comparison within each stent group. Analysis of variance (ANOVA) was used for comparisons of the three stent groups. Ordinal measurements such as injury score, fibrin score, and inflammation score were analyzed using the Kruskal-Wallis test. Nonparametric results were presented as median and interquartile range. A value of $P<0.05$ was considered statistically significant.

\section{Results}

Analysis after stenting

Two stents were placed within two coronary arteries per swine. A total of 36 stents, including 12 THS, 12 ZES, and 12 BMS, were placed in the proximal left anterior descending and proximal circumflex artery for 18 swine. The mortality rate for this study was zero. There was no significant difference in stent-to-artery ratio among the three stent groups.

\section{Histopathologic analysis}

There were no significant differences in the injury score (2.0 [range 1.0 to 2.0 ] in the THS group vs. 2.0 [range 1.0 to 2.0] in the ZES group vs. 2.0 [range 2.0 to 2.0 ] in the BMS group, $P=\mathrm{NS}$ ) or internal elastic lamina $\left(5.1 \pm 0.52 \mathrm{~mm}^{2}\right.$ in the THS group vs. $5.1 \pm 0.55$ $\mathrm{mm}^{2}$ in the ZES group vs. $5.0 \pm 0.68 \mathrm{~mm}^{2}$ in the BMS group, $P=\mathrm{NS}$ ) among the three groups. There were significant differences in neointima area $\left(2.9 \pm 0.85 \mathrm{~mm}^{2}\right.$ in the THS group vs. $2.8 \pm 0.10 \mathrm{~mm}^{2}$ in
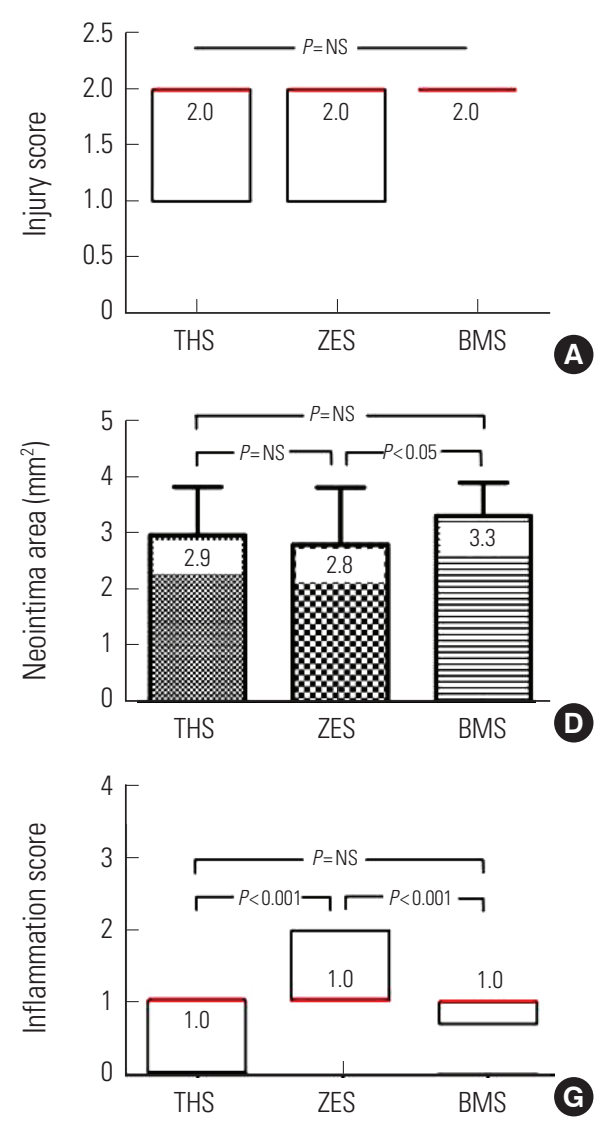
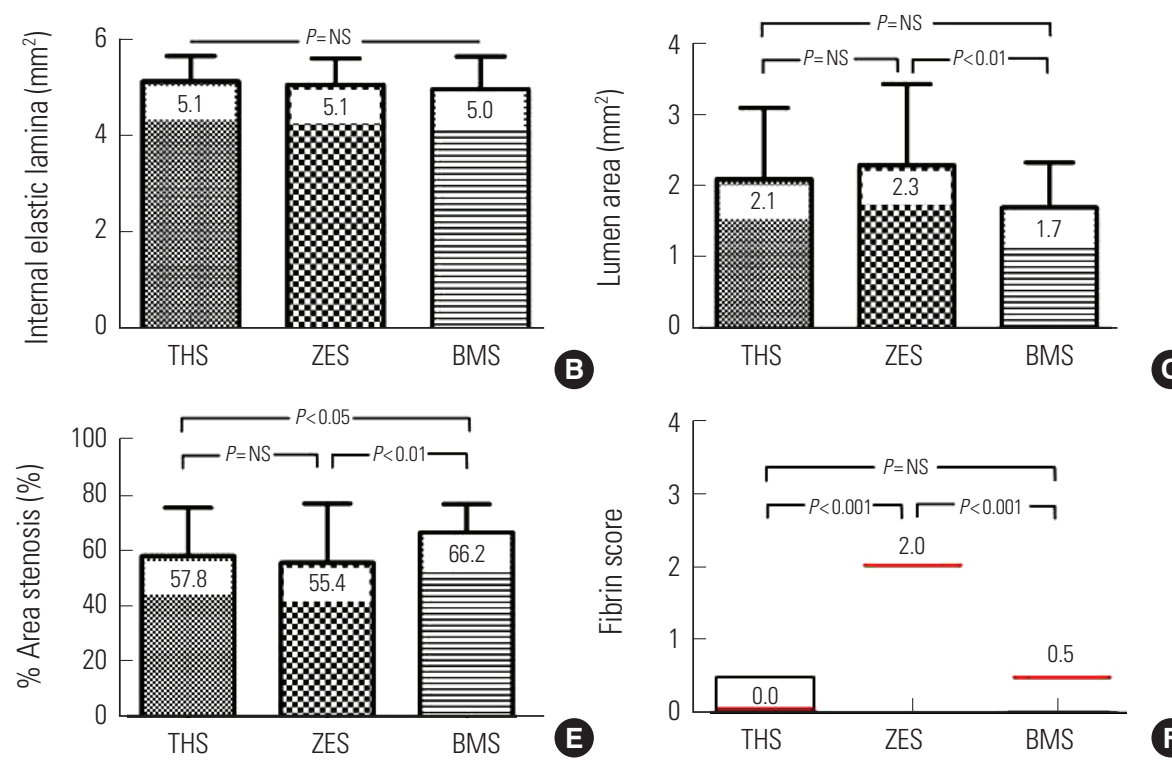

C

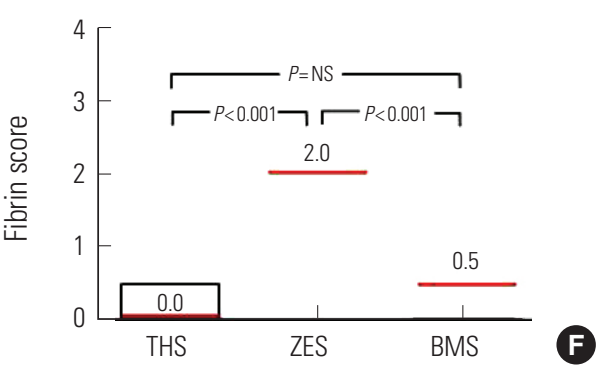

Fig. 3. Injury score $(A)$, internal elastic lamina $(B)$, lumen area $(C)$, neointima area $(D), \%$ area stenosis (E), fibrin score (F), and inflammation score (G) in THS, ZES, and BMS. A, F, and G are expressed as median (red color, interquartile range).

$\mathrm{THS}, \mathrm{TiO}_{2}$ film-heparin coated stent; ZES, zotarolimus-eluting stent with biocompatible polymer; BMS, bare metal stent. 

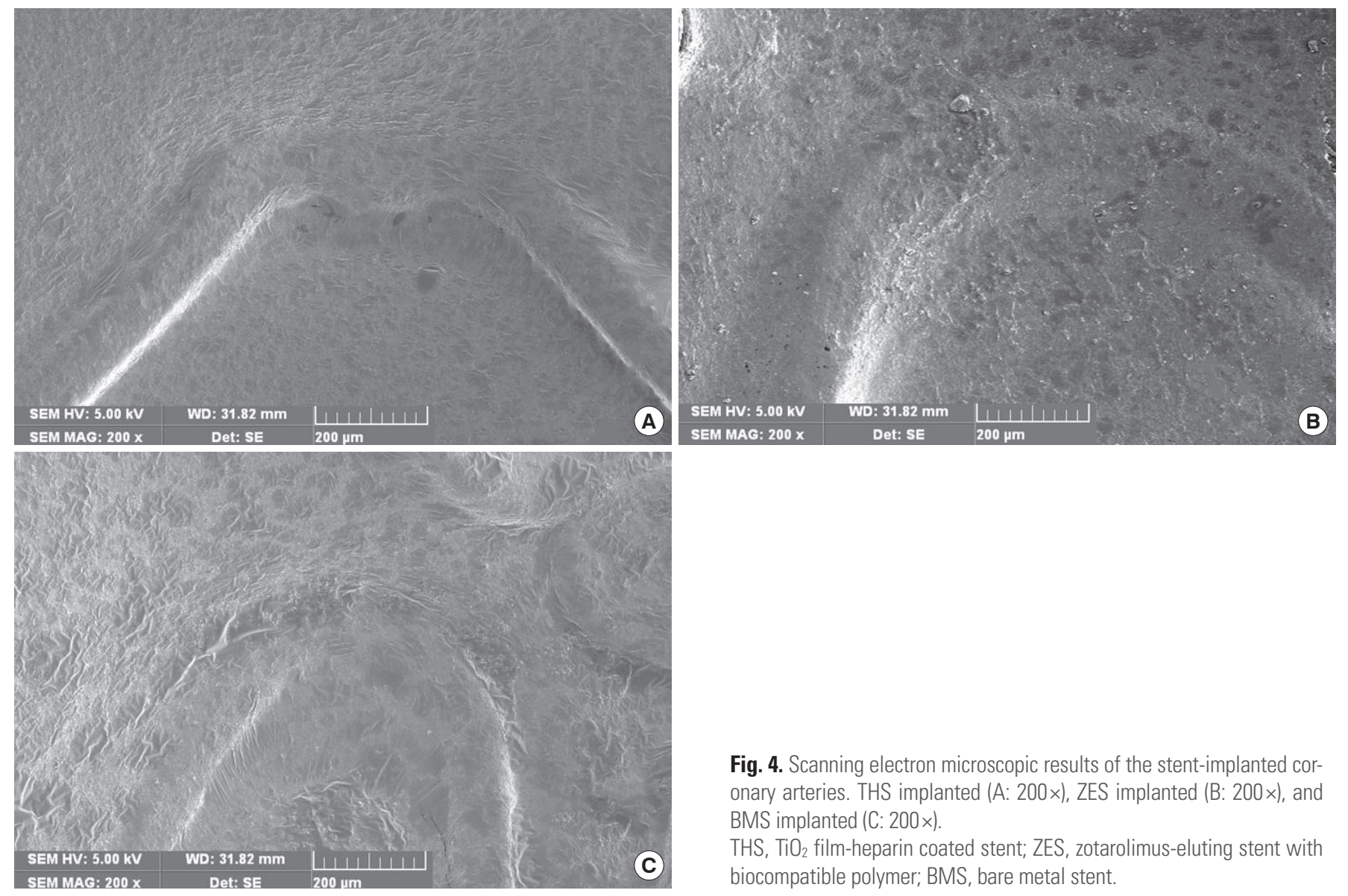

Fig. 4. Scanning electron microscopic results of the stent-implanted coronary arteries. THS implanted (A: 200x), ZES implanted (B: 200x), and BMS implanted (C: 200x).

$\mathrm{THS}, \mathrm{TiO}_{2}$ film-heparin coated stent; ZES, zotarolimus-eluting stent with biocompatible polymer; BMS, bare metal stent.

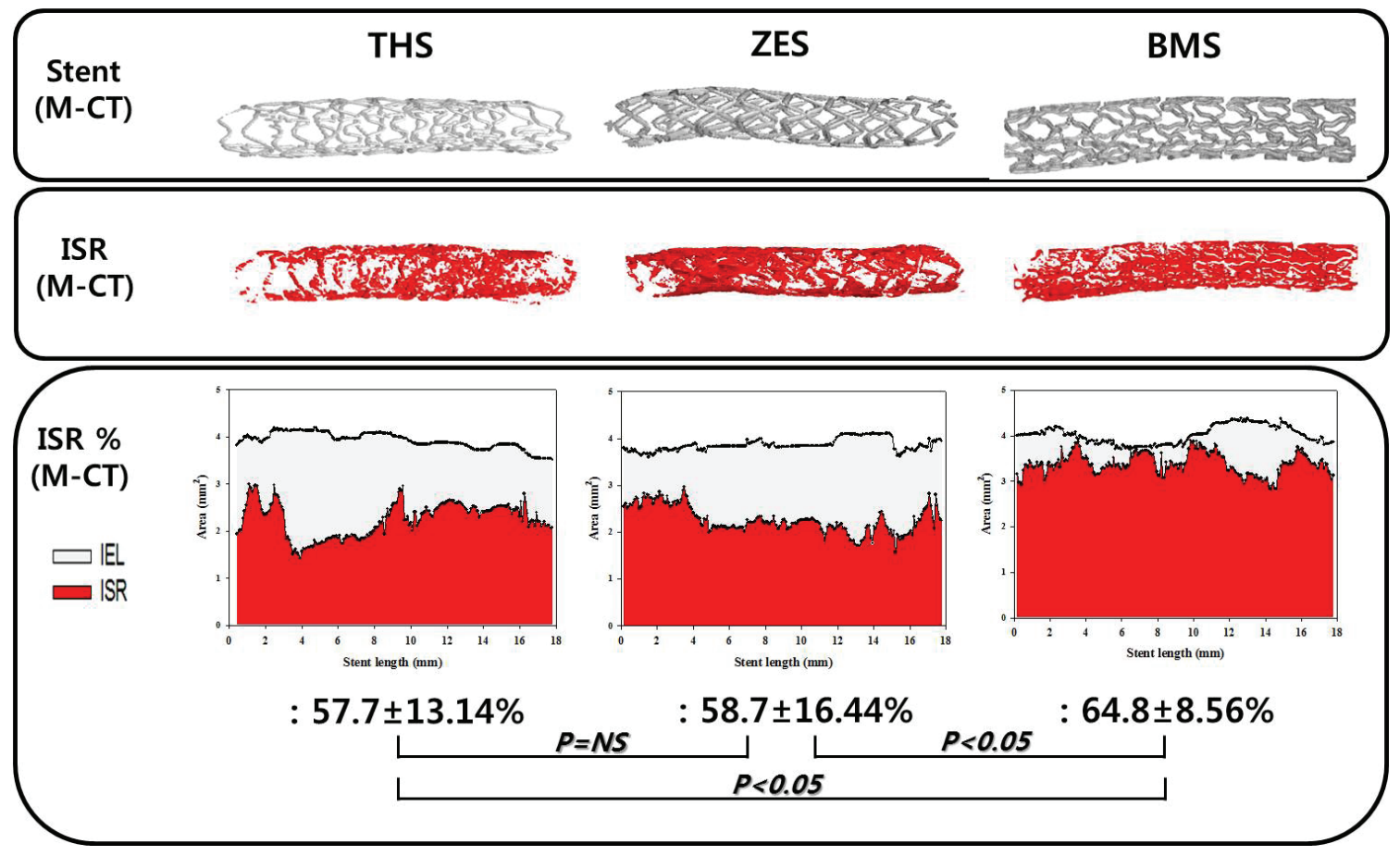

Fig. 5. Micro-computed tomography (M-CT) of in-stent restenosis (ISR) with THS, ZES, and BMS.

THS, $\mathrm{TiO}_{2}$ film-heparin coated stent; ZES, zotarolimus-eluting stent with biocompatible polymer; BMS, bare metal stent. 
the ZES group vs. $3.3 \pm 0.58 \mathrm{~mm}^{2}$ in the BMS group, $\left.P<0.05\right)$, lumen area $\left(2.1 \pm 0.10 \mathrm{~mm}^{2}\right.$ in the THS group vs. $2.3 \pm 1.14 \mathrm{~mm}^{2}$ in the ZES group vs. $1.7 \pm 0.63 \mathrm{~mm}^{2}$ in the BMS group, $P<0.05$ ), fibrin score $(0.0$ [range 0.0 to 1.0 ] in the THS group vs. 2.0 [range 2.0 to 2.0] in ZES group vs. 0.5 [range 0.0 to 2.0] in the BMS group, $P<0.0001$ ) (Fig. 1), inflammation score (1.0 [range 0.0-1.0] in the THS group vs. 1.0 [range 1.0 to 2.0 ] in the ZES group vs. 1.0 [range 0.75 to 1.0$]$ in the BMS group, $P<0.0001$ ) (Fig. 2), and percent area stenosis $(57.8 \pm 17.34 \%$ in the THS group vs. $55.4 \pm 21.22 \%$ in the ZES group $66.2 \pm 10.12 \%$ in the BMS group, $P<0.05$ ) among the three groups (Fig. 3).

Scanning electron microscopic analysis

SEM revealed complete stent strut coverage in all groups. There was no significant difference in strut coverage among the three stent groups (Fig. 4).

Micro computed tomography analysis

The in-stent restenosis rate of M-CT showed similar results with respect to percent area stenosis upon histopathologic analysis (57.7 \pm $13.14 \%$ in the THS group vs. $58.7 \pm 16.44 \%$ in the ZES group $64.8 \pm$ $8.56 \%$ in the BMS group, $P<0.05$ ) (Fig. 5 ).

\section{Discussion}

Our study was conducted to compare the THS $\left(\mathrm{TiO}_{2}\right.$ film-heparin coated stent), ZES (zotarolimus-eluting stent with biocompatible polymer), and BMS (bare metal stent) in a porcine coronary restenosis model. Our study showed that THS appeared to offer effective inhibition of the neointimal proliferation compared to BMS and a significantly lower fibrin score than the polymer-based ZES.

The cobalt-chromium alloy-based BMS can cause inflammatory reactions within the stented artery, which lead to neointima proliferation. ${ }^{19}$ Titanium is commonly used in biocompatible materials for medical implants, such as those used in dental and orthopedic fields, because it has excellent mechanical stability and good blood compatibility. $\mathrm{TiO}_{2}$ films have better blood compatibility compared to cobalt-chromium alloy. ${ }^{20}$ When $\mathrm{TiO}_{2}$ is coated onto a bare metal stent, it suppresses inflammation and inhibits blood coagulation. ${ }^{21}$ Therefore, we coated a $\mathrm{TiO}_{2}$ thin film onto a cobalt-chromium bare metal stent via plasma-enhanced chemical vapor deposition. Then, heparin was grafted onto the modified $\mathrm{TiO}_{2}$ film-coated stents through covalent bonding without polymer. ${ }^{13}$

In our previous study using non-polymeric titanium dioxide filmcoated stents with abciximab (TCA) or alpha lipoic acid (TCALA), a non-inferior neointima depressive effect was observed compared to commercial biolimus A9-eluting stent (BES), which used a bioabsorbable poly-lactic acid and strong immunosuppressive sirolimus derivatives. Moreover, TCA and TCALA showed significantly lower inflammation and fibrin scores than BES. ${ }^{22}$

In vitro study of zotarolimus demonstrated VSMCs and endothelial cell proliferation inhibition through binding to FKBP-12. The zotarolimus-eluting stent significantly reduced neointima hyperplasia in a porcine coronary restenosis model. ${ }^{23}$

In an in vitro study, heparin treatment on proliferating vascular smooth muscle cells (VSMCs) resulted in decreased ERK pathway signaling and suppressed VSMCs proliferation. Heparin treatment causes an elevation of cGMP level, which indicates a role for cGMPdependent protein kinase (PKG) in heparin-induced decreased VSMC proliferation. ${ }^{24}$

Heparin-coated balloon-expandable Palmaz-Schatz stents reduce neointima hyperplasia after iliac artery stenting of primates. ${ }^{25} \mathrm{~A}$ releasable heparin-coated stent supressed in-stent neointima proliferation in a porcine coronary restenosis model. ${ }^{26}$

Delayed arterial healing was defined as fibrin deposition surrounding the stent strut beyond four weeks after stenting. First-generation polymer-based DES, such as Cypher and Taxus, showed greater fibrin score and less re-endothelialization compared with BMS. The persistence of fibrin and poor re-endothelialization after stenting were observed for ST pathologic evaluation. Fibrin deposition suggests a potent thrombogenic stimulus. ${ }^{27}$ Polymers used for coronary stent coating are associated with vessel wall inflammatory reaction, restenosis, and late stent thrombosis.

Our result demonstrated that commercial ZES, a polymer-based drug delivery stent, yielded a greater delay of arterial healing than non-polymeric THS. Therefore, our developed THS will reduce the risk of ST compared to polymer-based DES.

This study shows that THS is more effective in reducing neointima formation compared to BMS. Moreover, the neointima suppressive effect of THS is superior to commercial polymer-based drug delivery ZES, with lower fibrin and inflammation scores as measured one month after stenting in a porcine coronary restenosis model.

\section{Study limitations}

Our study had some limitations. First, we used non-atherosclerotic normal porcine coronary arteries, unlike the likely human clinical situation with pre-existing atherosclerosis. Second, H\&E staining was used for evaluating inflammatory reaction; immunohistochemistry techniques are the standard for such studies. ${ }^{28}$ Third, long-term follow-up experiments, greater than six months in duration and using minipigs, were not performed.

\section{Acknowledgments}

This work was supported by a grant from the Korean Society on Thrombosis and Hemosatsis (KSTH 2016-001) and Basic Science Research Program through the National Research Foundation of Korea (NRF) funded by the Ministry of Education, Science and Technology (NRF-2017R1C1B1001956).

\section{Conflicts of interest}

The authors declare no conflicts of interest.

\section{References}

1. Wenaweser P, Daemen J, Zwahlen M, van Domburg R, Juni P, Vaina S, et al. Incidence and correlates of drugeluting stent thrombosis in routine clinical practice. 4-year results from a large 2-institutional cohort study.
J Am Coll Cardiol 2008·52:1134-40.

2. Stettler C, Wandel S, Allemann S, Kastrati A, Morice MC, Schomig A, et al. Outcomes associated with drugeluting and bare-metal stents: a collaborative network meta-analysis. Lancet 2007;370:937-48.

3. Murphy JG, Schwartz RS, Edwards WD, Camrud AR, Vlietstra RE, Holmes DR Jr. Percutaneous polymeric stents in porcine coronary arteries. Initial experience with polyethylene terephthalate stents. Circulation 1992 86:1596-604.

4. Nebeker JR, Virmani R, Bennett CL, Hoffman JM, Samore $\mathrm{MH}$, Alvarez J, et al. Hypersensitivity cases associated with drug-eluting coronary stents: a review of available cases from the Research on Adverse Drug 
Events and Reports (RADAR) project. J Am Coll Cardiol 2006;47:175-81.

5. Stone GW, Moses JW, Ellis SG, Schofer J, Dawkins $\mathrm{KD}$, Morice MC, et al. Safety and efficacy of sirolimus- and paclitaxel-eluting coronary stents. N Engl J Med 2007;356:998-1008.

6. Meredith IT, Ormiston J, Whitbourn R, Kay IP, Muller D, Bonan R, et al. First-in-human study of the Endeavor ABT-578-eluting phosphorylcholine-encapsulated stent system in de novo native coronary artery lesions: Endeavor I Trial. EuroIntervention 2005;1:157-64.

7. Leon MB, Nikolsky E, Cutlip DE, Mauri L, Liberman $\mathrm{H}$, Wilson $\mathrm{H}$, et al. Improved late clinical safety with zotarolimus-eluting stents compared with paclitaxeleluting stents in patients with de novo coronary lesions: 3-year follow-up from the ENDEAVOR IV (Randomized Comparison of Zotarolimus- and Paclitaxel-Eluting Stents in Patients With Coronary Artery Disease) trial. JACC Cardiovasc Interv 2010;3:1043-50.

8. Vrolix MC, Legrand VM, Reiber JH, Grollier G, Schalij MJ, Brunel P, et al. Heparin-coated Wiktor stents in human coronary arteries (MENTOR trial). MENTOR Trial Investigators. Am J Cardiol 2000;86:385-9.

9. Chen H, Chen Y, Sheardown H, Brook MA. Immobilization of heparin on a silicone surface through a heterobifunctional PEG spacer. Biomaterials 2005;26:741824

10. Ahn YK, Jeong MH, Kim JW, Kim SH, Cho JH, Cho JG, et al. Preventive effects of the heparin-coated stent on restenosis in the porcine model. Catheter Cardiovasc Interv 1999;48:324-30.

11. Bae IH, Park IK, Park DS, Lee H, Jeong MH. Thromboresistant and endothelialization effects of dopaminemediated heparin coating on a stent material surface. J Mater Sci Mater Med 2012;23:1259-69.

12. Cho JY, Ahn Y, Jeong MH. A bumpy and winding but right path to domestic drug-eluting coronary stents. Korean Circ J 2013;43:645-54

13. Song SJ, Park YJ, Park J, Cho MD, Kim JH, Jeong MH et al. Preparation of a drug-eluting stent using a TiO film deposited by plasma enhanced chemical vapour deposition as a drug-combining matrix. J Mater Chem 2010;20:4792-801.

14. Schwartz RS, Huber KC, Murphy JG, Edwards WD Camrud AR, Vlietstra RE, et al. Restenosis and the proportional neointimal response to coronary artery injury: results in a porcine model. J Am Coll Cardio 1992;19:267-74

15. Che HL, Bae IH, Lim KS, Song IT, Lee H, Muthiah M, et al. Suppression of post-angioplasty restenosis with an Akt1 siRNA-embedded coronary stent in a rabbi model. Biomaterials 2012;33:8548-56.

16. Farb A, Tang AL, Shroff S, Sweet W, Virmani R. Neointimal responses 3 months after (32)P beta-emitting stent placement. Int J Radiat Oncol Biol Phys 2000;48 889-98.

17. Schwartz RS, Edelman E, Virmani R, Carter A, Granada JF, Kaluza GL, et al. Drug-eluting stents in preclinical studies: updated consensus recommendations for preclinical evaluation. Circ Cardiovasc Interv 2008; 143-53.

18. Suzuki T, Kopia G, Hayashi S, Bailey LR, Llanos G, Wilensky R, et al. Stent-based delivery of sirolimus reduces neointimal formation in a porcine coronary model. Circulation 2001;104:1188-93.

19. Koster R, Vieluf D, Kiehn M, Sommerauer M, Kahler J, Baldus S, et al. Nickel and molybdenum contact allergies in patients with coronary in-stent restenosis. Lancet 2000;356:1895-7.

20. Hanawa T, Asami K, Asaoka K. Repassivation of titanium and surface oxide film regenerated in simulated bioliquid. J Biomed Mater Res 1998;40:530-8.
21. Nan H, Ping Y, Xuan C, Yongxang L, Xiaolan Z, Guangjun $\mathrm{C}$, et al. Blood compatibility of amorphous titanium oxide films synthesized by ion beam enhanced deposition. Biomaterials 1998;19:771-6.

22. Lim KS, Jeong MH, Bae IH, Park JK, Park DS, Kim $\mathrm{JM}$, et al. Effect of polymer-free $\mathrm{TiO}_{2}$ stent coated with abciximab or alpha lipoic acid in porcine coronary restenosis model. J Cardiol 2014;64:409-18.

23. Garcia-Touchard A, Burke SE, Toner JL, Cromack K, Schwartz RS. Zotarolimus-eluting stents reduce experimental coronary artery neointimal hyperplasia after 4 weeks. Eur Heart J 2006;27:988-93.

24. Gilotti AC, Nimlamool W, Pugh R, Slee JB, Barthol TC, Miller EA, et al. Heparin responses in vascular smooth muscle cells involve cGMP-dependent protein kinase (PKG). J Cell Physiol 2014;229:2142-52.

25. Lin PH, Chronos NA, Marijianowski MM, Chen C, Bush RL, Conklin B, et al. Heparin-coated balloon-expandable stent reduces intimal hyperplasia in the iliac artery in baboons. J Vasc Interv Radiol 2003;14:603 11.

26. Matsumoto Y, Shimokawa H, Morishige K, Eto Y, Takeshita A. Reduction in neointimal formation with a stent coated with multiple layers of releasable heparin in porcine coronary arteries. J Cardiovasc Pharmacol 2002;39:513-22.

27. Joner M, Finn AV, Farb A, Mont EK, Kolodgie FD, Ladich E, et al. Pathology of drug-eluting stents in humans: delayed healing and late thrombotic risk. J Am Coll Cardiol 2006;48:193-202.

28. Malik N, Gunn J, Holt CM, Shepherd L, Francis SE, Newman CM, et al. Intravascular stents: a new technique for tissue processing for histology, immunohistochemistry, and transmission electron microscopy. Heart 1998;80:509-16. 